\title{
Wavelet analysis of the seismograms for tsunami warning
}

\author{
A. Chamoli ${ }^{1}$, V. Swaroopa Rani ${ }^{1}$, K. Srivastava ${ }^{1}$, D. Srinagesh ${ }^{1}$, and V. P. Dimri ${ }^{2}$ \\ ${ }^{1}$ National Geophysical Research Institute (Council of Scientific \& Industrial Research), Hyderabad-500007, India \\ ${ }^{2}$ Gujarat Energy Research \& Management Institute, Research, Innovation \& Incubation Centre, Gandhinagar 382 007, India
}

Received: 22 July 2010 - Revised: 20 September 2010 - Accepted: 25 September 2010 - Published: 12 October 2010

\begin{abstract}
The complexity in the tsunami phenomenon makes the available warning systems not much effective in the practical situations. The problem arises due to the time lapsed in the data transfer, processing and modeling. The modeling and simulation needs the input fault geometry and mechanism of the earthquake. The estimation of these parameters and other aprior information increases the utilized time for making any warning. Here, the wavelet analysis is used to identify the tsunamigenesis of an earthquake. The frequency content of the seismogram in time scale domain is examined using wavelet transform. The energy content in high frequencies is calculated and gives a threshold for tsunami warnings. Only first few minutes of the seismograms of the earthquake events are used for quick estimation. The results for the earthquake events of Andaman Sumatra region and other historic events are promising.
\end{abstract}

\section{Introduction}

Tsunami is a complex phenomenon to understand and its complexity lies in all the stages of a tsunami, i.e., generation, propagation, runup and inundation. The recent devasting and gaint tsunami which occurred in the Sunda trench (26 December 2004) has opened the Pandora's box in the Andaman-Sumatra subduction zone. Apart from the precise alert/warning system, it has altered entire scientific community in the world. There are several methods available to detect tsunamis and its near-field and far-field impact, but these are time consuming and difficult to apply in the practical and real situations. One approach which is widely and generally used by the early warning systems/centers for the detection of tsunamigenic and non-tsunamigenic earthquakes is by re-

Correspondence to: A. Chamoli

(chamoli.a@gmail.com) ceiving the information from the DART buoys deployed in the deep oceans. The tsunami has to reach these buoys, then transfer of tsunami water level information to the early warning centers, processing this data and issuing warning takes time. Another accurate approach which is used by several researchers in this field is modeling of all the stages of tsunami propagation and simulation of tsunami wave heights and runup heights at the far-field locations before the arrival of the tsunami. But this method needs precise magnitude estimation and fault parameters, i.e., strike (orientation of the fault), dip, rake, slip magnitude and focal depth. This method is appropriate to understand tsunami behaviour and to estimate far-field (impact) effects, but not suitable to issue early warnings. The time of the arrival of tsunami at the coastal areas nearby epicentral region is less compared to the time taken for the simulation process.

Extensive research for seismogram analysis in the spectral domain has shown fast complimentary approach (Shapiro et al., 1998). Wavelet transform was first introduced by Morlet et al. (1982a, b), Grossmann and Morlet (1984) and Goupilloud et al. (1984) and is being used as a powerful signal analysis tool in the different fields of applications such as denoising, compression, time-frequency analysis, climate studies etc (Foufoula-Georgiou and Kumar, 1994; Chamoli et al., 2007, 2010; Torrence and Compo, 1998). Wavelet transform is a localized transform in both time and frequency, which is more relevant than conventional methods to extract information from a non-stationary signal.

In seismology, wavelet transform has been used by different workers for seismogram analysis, earthquake parameter determination, tsunami warning (Simons et al., 2006; Lockwood and Kanamori, 2006; Chew and Kuenza, 2009). The arrival of the seismic waves to the seismic stations is much faster than tsunami and this information can be used for warning. There are some wavelet based methodologies reported in the last few years for tsunami warning. Lockwood and Kanamori (2006) used wavelet analysis to identify

Published by Copernicus Publications on behalf of the European Geosciences Union and the American Geophysical Union. 
Table 1. Earthquake events used in the present study and the values of average slip, rupture duration and calculated "max $E_{a}$ " parameters. Category I are tsunamigenic and II are nontsunamigenic events.

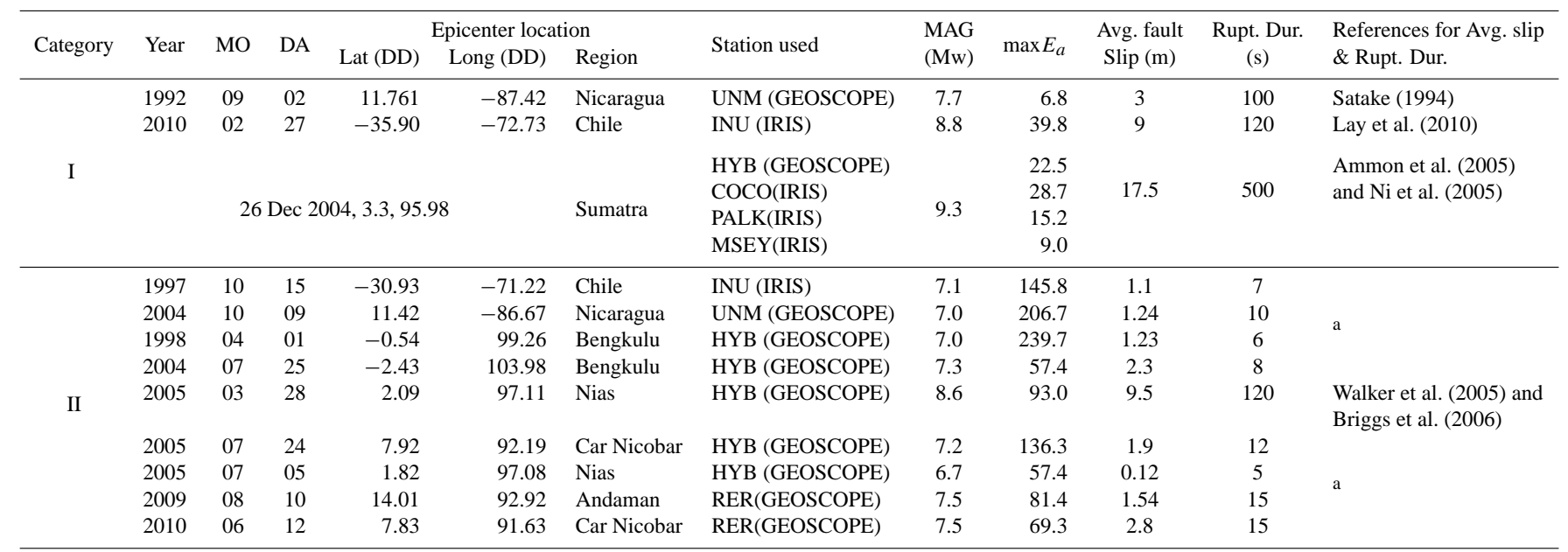

a Average fault slip ( $\mathrm{S}=\mathrm{Mo} / \mu \mathrm{A})$ were estimated by the empirical relation given by Wells and Coppersmith (1994) and rupture duration were taken from USGS (http://earthquake. usgs.gov/research/data/pde.php).

the W-phase (a long period phase), which characterizes the tsunamigenic earthquake. The presence of $\mathrm{W}$-phase is only at very far stations and thus, put a constrain for early warning. Chew and Kuenza (2009) have reported the high frequency content in the wavelet spectrum using all phases of a seismogram.

The Andaman-Sumatra subduction zone (Fig. 1) is one of the active plate tectonic margins in the world accommodating over $50 \mathrm{~mm} /$ year (Stein and Okal, 2005) of oblique northward convergence between the South-Asian and IndianAustralian plates, which arcs $5500 \mathrm{~km}$ from Myanmar past Sumatra and Java towards Australia. Sumatra earthquake of 26 December 2004 (Mw 9.3) was felt globally, e.g., in Indonesia and neighboring countries like India, Sri Lanka and Africa and affected 12 countries from Indonesia to Somalia. Nias earthquake 28 March 2005 (Mw 8.6) in the same region didn't generate a major tsunami. Various major earthquake events are generated in this region. It is important to distinguish the tsunamigenic earthquake from nontsunamigenic earthquakes for such region.

In this study, we have shown a simple diagnostic method for distinguishing the tsunamigenic and non-tsunamigenic earthquake based on the frequency content in wavelet domain (time scale domain). The frequency content of the seismogram is analysed for different tsunamigenic and nontsunamigenic earthquakes considering only first few minutes of the P-wave train which could help in early warnings. The seismograms of the earthquake events mostly from Andaman-Sumatra region are used for illustration of the methodology.

\section{Data used and methodology}

The seismograms recorded by the GEOSCOPE station at National Geophysical Research Institute (NGRI), Hyderabad and IRIS stations are mainly used in the present study to minimize the path effect and the better comparison of the results. The Sumatra Earthquake of 26 December 2004 caused severe hazard in different countries and revealed the importance and need of warning systems to minimize the casualties. The high quality recording of the seismograms of this earthquake at different stations of different countries motivated studies to understand the physical characteristics and develop new methodology (Menke and Levin, 2005; Lomax and Michelini, 2005; Bormann and Welegalla, 2005; Blewitt et al., 2006). Other global tsunamigenic and nontsunamigenic events are also used for testing of the methodology. The details of the seismic events used in the study are presented in Table 1. The average fault slips are taken from different sources (for reference, please see the Table 1). For remaining events, the rupture area and fault slip are estimated by the empirical relation given by Wells and Coppersmith (1994). All the earthquakes tabulated in Table 1 are recorded at $20 \mathrm{~Hz}$ sampling frequency at different stations.

The location of the epicenters and recording stations considered in our analysis is shown in Fig. 1. It shows the epicenters of earthquakes with magnitude greater than 7.0 from different subduction zones considered in this study. We have analyzed earthquake events from Bengkulu, Nias, Sumatra and Andaman Nicobar segments of Andaman-Sumatra region and also the significant earthquakes of Chile and Nicaragua (Table 1). The first few minutes (less than $5 \mathrm{~min}$ in most cases) comprising the $\mathrm{P}$-wave train of the seismograms 

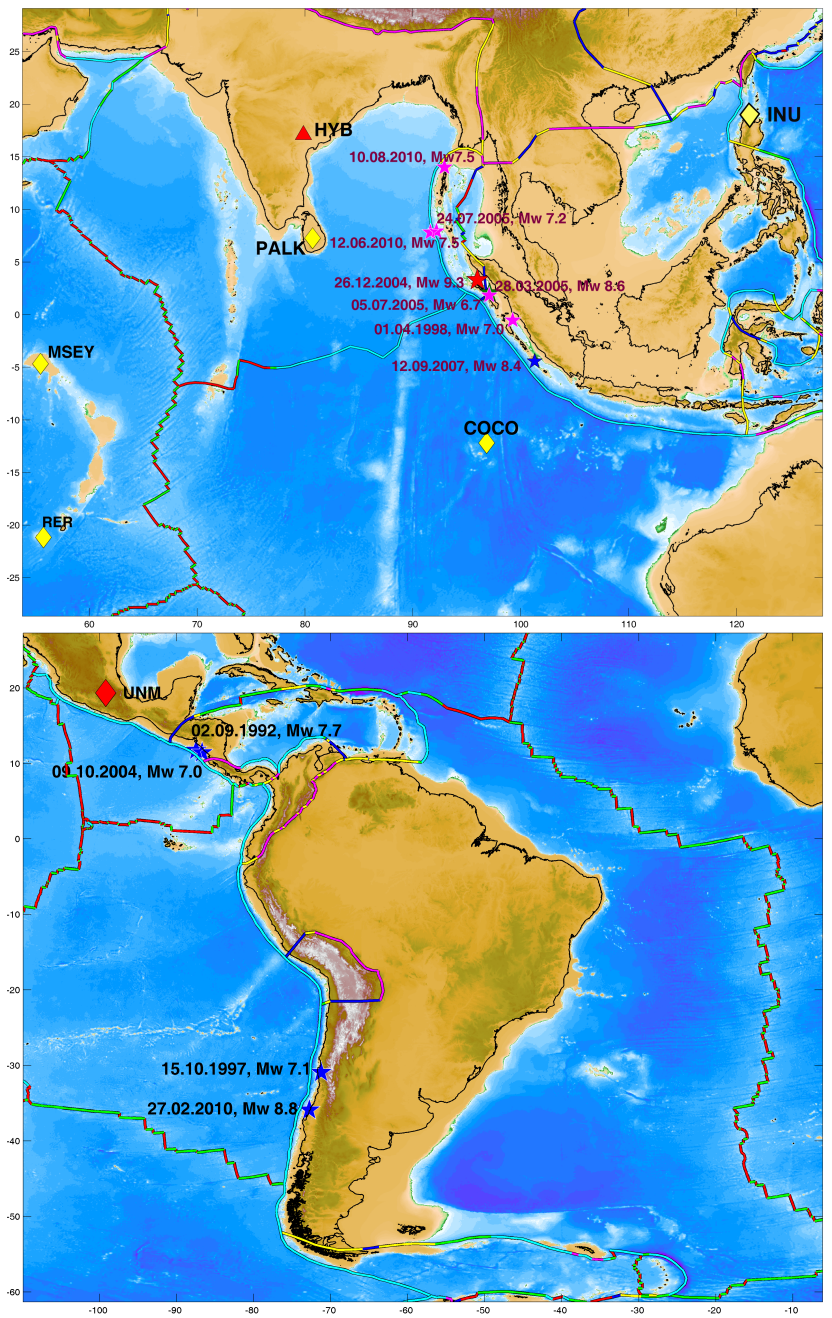

Fig. 1. The epicenter and seismic stations of IRIS (diamond symbol) and Geoscope (triangle symbol) used in our analysis.

are used to quantify the frequency content in high frequencies more than $0.33 \mathrm{~Hz}$.

The applications of the wavelet analysis are vast in different fields of signal processing. In the wavelet analysis, the scaled and translated wavelets are used, which make it suitable for studying the nonstationary signals. Significant information can be extracted simultaneously in time as well as frequency domain due to time-frequency localization property of the wavelets. Due to this time frequency localization property, the wavelet transform gives better decomposition of signal in spectral domain than the conventional Fourier transform or windowed Fourier transform. Wavelet transform uses wavelength adaptive convolution operators that are optimal on the basis of wavelength of the studied portion of a signal. It allows the analysis of both local as well as global features and thus, acts as a microscope in spectral analysis. The seismograms are nonstationary waveforms and can be dealt accordingly in wavelet analysis.

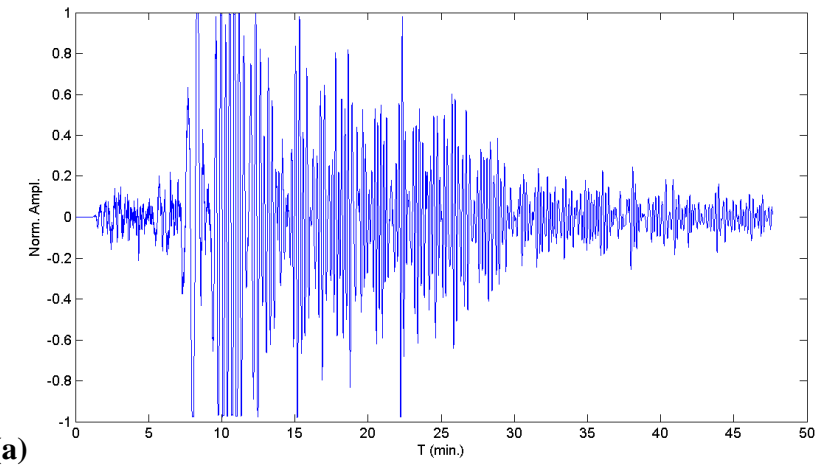

(b)

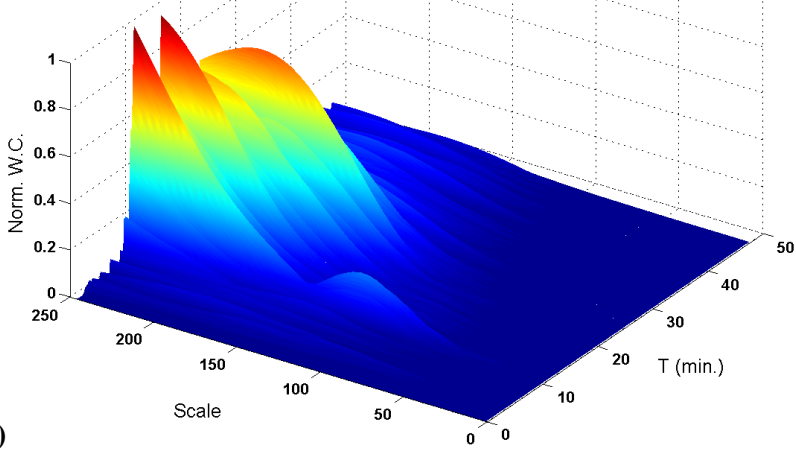

Fig. 2. Wavelet Analysis of Sumatra Earthquake (26 December 2004). The figure shows (a) seismogram, (b) wavelet spectrum.

The continuous wavelet transform of a function $f(t)$ is mathematically given as

$W_{\psi \mid f}(a, b)=\int_{-\infty}^{+\infty} \frac{1}{\sqrt{a}} \psi^{*}\left(\frac{t-b}{a}\right) f(t) d t, \quad a, b \in R, a>0$ (1)

where $\psi^{*}$ is complex conjugate of analyzing wavelet $\psi(t)$ which is also known as mother wavelet or kernel wavelet, $a$ is the scale parameter, which is inversely proportional to frequency and $b$ is the translation parameter. The value of $1 / \sqrt{a}$ is used to normalize the energy of the function at various scales (Daubechies, 1992). We have used Morlet wavelet due to good localization in time and frequency and tested applications in different fields (Grinsted et al., 2004; Morlet et al., 1982a, b; Wang, 2006). The wavelet coefficients are calculated for the first few minutes of the seismograms and the sum of wavelet coefficients $(W)$ for high frequency content (more than $0.33 \mathrm{~Hz}$ ) are used for identifying the tsunamigenesis. In this high frequency band, the total energy corresponding to the high frequency of the signal at different times can be presented as

$E_{a}=\sum_{a}|W|^{2}$

The total energy $\left(E_{a}\right)$ at different times for the frequencies more than $0.33 \mathrm{~Hz}$ is calculated for characterizing the 
(a)

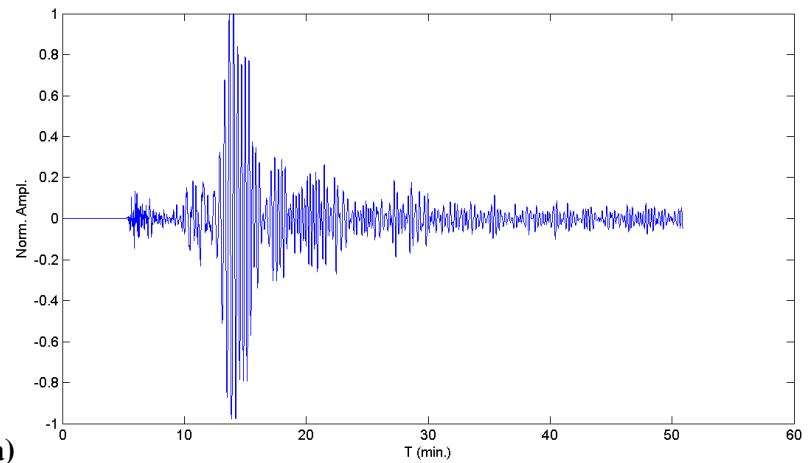

(b)

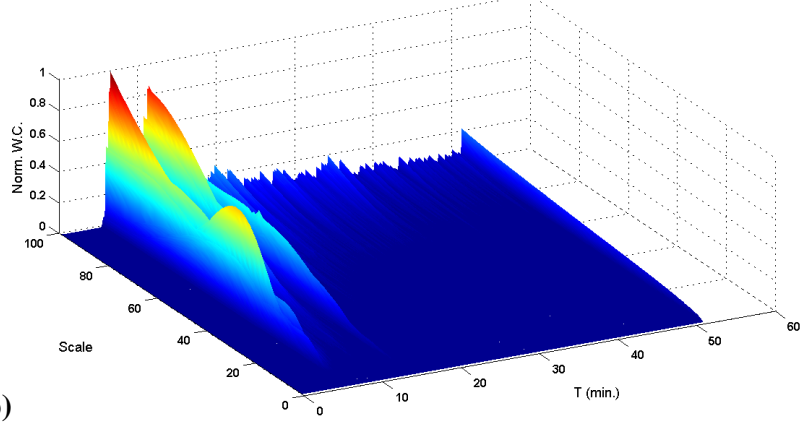

Fig. 3. Wavelet analysis of Nias 28 March 2005. The figure shows (a) seismogram, (b) wavelet spectrum.
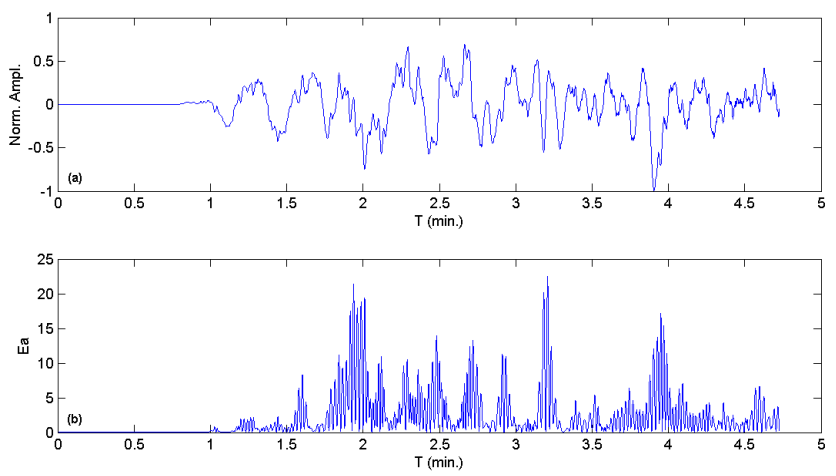

Fig. 4. (a) Seismogram of P-wave train; (b) Ea variation for Sumatra earthquake (26 December 2004).

tsunamigenesis. The parameter used to distinguish tsunamigenic and nontsunamigenic earthquake is " $\max E_{a}$ " which is the maximum value of $E_{a}$ among all times.

\section{Results and discussion}

The wavelet spectrum of various seismograms show a distinct behavior of the wavelet coefficients for frequencies greater than $0.33 \mathrm{~Hz}$ (scale 50) and we have studied it in detail. Tsunamigenic earthquakes are not showing any significant amplitude for frequencies greater than $0.33 \mathrm{~Hz}$. However, the amplitude/energy for these frequencies is significant for nontsunamigenic earthquakes. The wavelet spectrum of
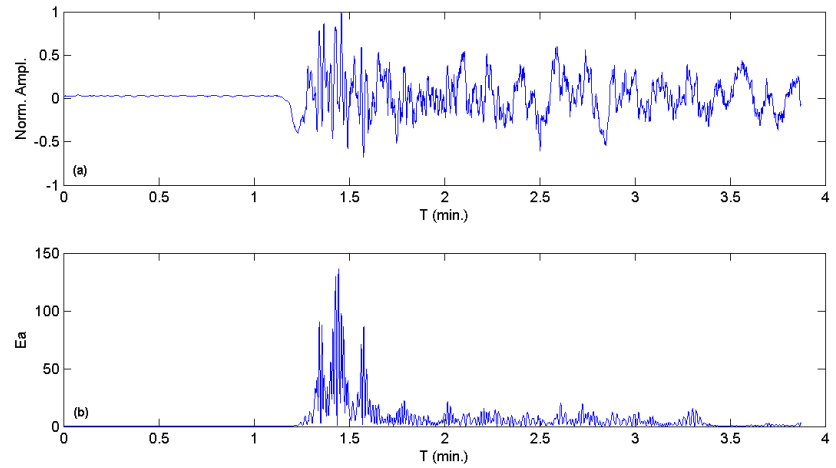

Fig. 5. (a) Seismogram of P-wave train; (b) Ea variation for Car Nicobar earthquake (24 July 2005).

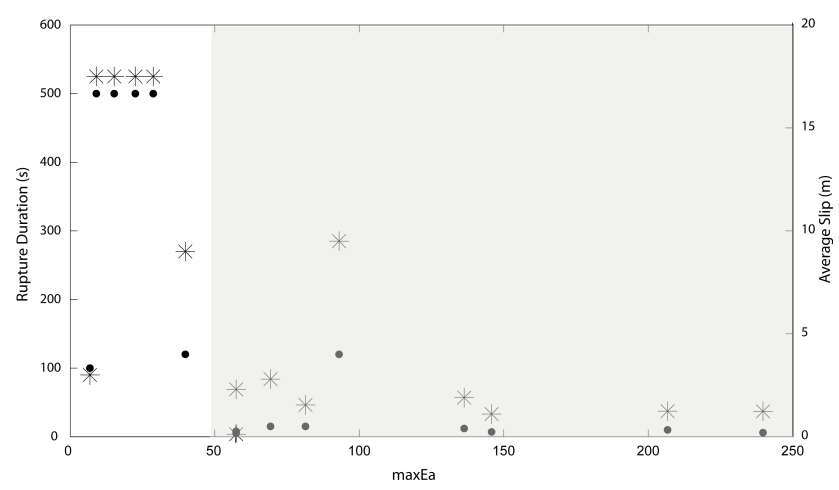

Fig. 6. The plot shows the average fault slip (as star), "max $E_{a}$ " and rupture duration (as dots) for the events in Table 1.

the Sumatra Earthquake 2004 (tsunamigenic) and Car Nicobar 2005 (nontsunamigenic) is shown in Figs. 2 and 3, respectively, for illustration, which clearly shows the absence of high frequencies for tsumigenic earthquake, which are present for nontsunamigenic earthquake. The similar characteristic is observed for other seismograms considered in the study. The total energy $E_{a}$ for the frequency 0.33 to $16.25 \mathrm{~Hz}$ is calculated for different seismograms. For illustration, the $E_{a}$ variation with time of Sumatra earthquake (26 December 2004) and Car Nicobar Earthquake (2005) is shown in Figs. $4 \mathrm{~b}$ and $5 \mathrm{~b}$, respectively. The high peaks of $E_{a}$ are observed for nontsunamigenic events. The calculated values of "max $E_{a}$ " are given in Table 1 for different seismograms. The " $\max E_{a}$ " values represent the energy of the portion of seismogram for the frequencies more than $0.33 \mathrm{~Hz}$. The value of "max $E_{a}$ " varies from 6.8 to 39.8 for tsunamigenic events and 57.4 to 239.7 for nontsunamigenic events. The values are comparatively high (more than 2 times) for nontsunamigenic events and thus, can be used for identifying tsunamigenesis. Category-I and II in Table 1 classify the tsunamigenic and nontsunamigenic events, respectively. The statistical significance of the "max $E_{a}$ " values for category-I and II (Table 1) are checked using the standard "t-test". The calculated " $t$ " 
value $(\sim 3.6)$ is much greater than the critical value of " $\mathrm{t}$ " for 13 degree of freedom at 5\% level of significance for right tailed test. Thus, we reject the null hypothesis $\left(H_{0}: \mu_{1}=\mu_{2}\right.$, where $\mu_{1}$ and $\mu_{2}$ are mean of two categories respectively) at 5\% level of significance and conclude that category - I have average "max $E_{a}$ " value more than category- II $\left(H_{0}\right.$ : $\left.\mu_{1}>\mu_{2}\right)$. Figure 6 shows the rupture duration and average slip verses "max $E_{a}$ ", which indicates that the relatively high rupture duration and slip characterizes the tsunamigenic earthquake and opposite for nontsunamigenic earthquakes (Fig. 6, shaded region).

The frequency content of the tsunamigenic earthquakes reflects the slow and large slip behaviour (Vidale and Houston, 1993). Sumatra 2004 have slip $\sim 15-20 \mathrm{~m}$ and rupture duration $\sim 500 \mathrm{~s}$ (Ammon et al., 2005), whereas Nias Earthquake 2005 have slip $\sim 8-11 \mathrm{~m}$ and rupture duration $\sim 110-130 \mathrm{~s}$ (Table 1). The rupture duration for large non-tsunamigenic earthquakes $\sim 11 \mathrm{~s}$ while for tsunamigenic exceeds $1 \mathrm{~min}$ (Vidale and Houston, 1993). The slip distribution is generally derived from the modeling of low frequency wave. The low frequency content is related to the large slip. Further, source-rupture duration is derived from high frequency radiation pattern. This correlates the high frequency energy depletion with the long rupture duration. Thus, the absence of high frequencies in tsunamigenic earthquakes can be attributed to the long rupture duration, while the presence of low frequencies reflects the slow and large slip.

The wavelet analysis of earthquake events gives a methodology for tsunami warning based on the frequency content of the seismogram. The absence of high frequencies in tsunamigenic earthquakes is due to the large slip and slow rupture. This behavior is well manifested in the frequency domain. The wavelet transform is a promising tool to identify and quantify these frequencies in time-scale domain. The method is fast and overcome the problems of conventional tsunami warning methods in practical situations. The method uses only the first few minutes P-train, which adds the speed in calculations. The " $\max E_{a}$ " parameter which represents the total energy above $0.33 \mathrm{~Hz}$, can be used as a threshold parameter for tsunami warning.

Acknowledgements. We thank the editor and anonymous reviewers for their constructive comments for improvement of the manuscript. We are thankful to the IRIS Data Management System, Seattle, Washington and GEOSCOPE (http://geoscope.ipgp.fr/index.php/en) for providing the data for the study.

Edited by: A. Bunde

Reviewed by: two anonymous referees

\section{References}

Ammon, C. J., Chen Ji, Thio, H. K., David, R., Sidao Ni, Vala Hjorleifsdottir, Kanamori, H., Lay, T., Shamita Das, Das Helmberger, Ichinose, G., Polet, J., and Wald, D.: Rupture Process of the 2004 Sumatra-Andaman Earthquake, Science, 308, 1133-1139, 2005.

Blewitt, G., Kreemer, C., Hammond, W. C., Plag, H. P., Stein, S., and Okal, E. A.: Rapid determination of earthquake magnitude using GPS for tsunami warning systems, Geophys. Res. Lett., 33, L11309, doi:10.1029/2006GL026145, 2006.

Bormann, P. and Welegalla, K. G.: Quick estimator of the size of great earthquakes, EOS Trans. AGU, 86(41), 464, doi:10.1029/2005EO460005, 2005.

Briggs, R. W., Sieh, K., Meltzner, A. J., Natawidjaja, D., Galetzka, J., Suwargadi, B., Hsu, Y., Simons, M., Hananto, N., Suprihanto, I., Prayudi, Dudi., Avouac, J. P., Prawirodirdjo, L., and Bock, Y.: Deformation and Slip Along the Sunda Megathrust in the Great 2005 Nias-Simeulue Earthquake, Science, 311, 18971901, 2006.

Chamoli, A., Bansal, A. R., and Dimri, V. P.: Wavelet and rescaled range approach for the Hurst coefficient for short and long time series, Comput. Geosci., 33, 83-93, 2007.

Chamoli, A., Pandey, A. K., Dimri, V. P., and Banerjee, P.: Crustal Configuration of the Northwest Himalya Based on Modeling of Gravity Data, Pur. Appl. Geoph., doi:10.1007/s00024-010-01492 (online first), 2010.

Chew, S. H. and Kuenza, K.: Detecting tsunamigenesis from undersea earthquake signals, J. Asian Earth Sciences, 36, 84-92, 2009.

Daubechies, I.: Ten Lectures on Wavelets, CBMS-NSF Regional Conferences Series in Applied Mathematics, No. 61, SIAM, Philadelphia, 1992.

Foufoula-Georgiou, E. and Kumar, P.: Wavelets in Geophysics, Academic Press, San Deigo, California, 1944.

Goupillaud, P., Grossmann, A., and Morlet, J.: Cycle-octave and related transforms in seismic signal analysis, Geoexploration, 23, 85-102, 1984.

Grinsted, A., Moore, J. C., and Jevrejeva, S.: Application of the cross wavelet transform and wavelet coherence to geophysical time series, Nonlin. Processes Geophys., 11, 561-566, doi:10.5194/npg-11-561-2004, 2004.

Grossmann, A. and Morlet, J.: Decomposition of Hardy functions into square integrable wavelets of constant shape, SIAM J. Math. Anal., 15(4), 723-736, 1984.

Lay, T., Ammon, C. J., Kanamori, H., Koper, K. D., Sufri, O., and Hutko, A. R.: Teleseismic inversion for rupture process of the 27 February 2010 Chile (Mw 8.8) earthquake, Geophys. Res. Lett., 37, L13301, doi:10.1029/2010GL043379, 2010.

Lockwood, O. G. and Kanamori, H.: Wavelet analysis of the seismograms of the 2004 Sumatra-Andaman earthquake and its application to tsunami early warning, Geochemistry Geophysics Geosystems, 7(9), Q09013(1-10), doi:10.1029/2006GC001272, 2006.

Lomax, A. and Michelini, A.: Rapid determination of earthquake size for hazard warning, EOS Trans. AGU, 86(21), 202-203, 2005.

Menke, W. and Levin, V.: A strategy to rapidly determine the magnitude of great earthquakes, EOS Trans. AGU, 86(19), 185-189, 2005.

Morlet, J., Arens, G., Fourgeau, E., and Giard, D.: Wave propaga- 
tion and sampling theory - part 1: complex signal and scattering in multilayered media, Geophysics, 47(2), 203-221, 1982a.

Morlet, J., Arens, G., Fourgeau, E., and Giard, D.: Wave propagation and sampling theory - part 2: sampling theory and complex waves, Geophysics, 47(2), 222-236, 1982b.

Ni, S., Kanamori, H., and Helmberger, D.: Energy radiation from the Sumatra earthquake, Nature, 434, 582-582, 2005.

Satake, K.: Mechanism of the 1992 Nicaragua tsunami earthquake, Geophys. Res. Lett., 21(23), 2519-2522, 1994.

Shapiro, N. M., Singh, S. K., and Pacheco, J.: A fast and simple diagnostic for identifying tsunamigenic earthquakes, Geophys. Res. Lett., 25(20), 3911-3914, 1998.

Simons, F. J., Ben, D. E. D., and Richard, M. A.: Automatic detection and rapid determination of earthquake magnitude by wavelet multiscale analysis of the primary arrival, Earth Planet. Sci. Lett., 250, 214-223, 2006.
Stein, S. and Okal, E. A.: Speed and size of the Sumatra earthquake, Nature, 434, 581-582, 2005.

Torrence, C. and Compo, G. P.: A practical guide to wavelet analysis, B. Am. Meteorol. Soc., 79(1), 61-78, 1998.

Vidale, J. E. and Houston, H.: The depth dependence of earthquake duration and implications for rupture mechanisms, Letters to Nature, 365, 45-47, 1993.

Walker, K. T., Ishii, M., and Shearer, P. M.: Rupture details of the 28 March 2005 Sumatra Mw 8.6 earthquake imaged with teleseismic P waves, Geophys. Res. Lett., 32, L24303, doi:10.1029/2005GL024395, 2005.

Wang, Y.: Seismic time-frequency spectral decomposition by matching pursuit, Geophysics, 72, V13-V20, 2007.

Wells, D. L. and Coppersmith, K. J.: New Empirical Relationships among Magnitude, Rupture Length, Rupture Width, Rupture Area, and Surface Displacement, Bull. Seismol. Soci. Am., 84(4), 974-1002, 1994. 